\title{
Hypoglycaemia: the limiting factor in the glycaemic management of the critically ill?
}

\author{
P. E. Cryer
}

Published online: 7 June 2006

(C) Springer-Verlag 2006

In 2001, Van den Berghe and colleagues [1] reported reduced mortality and morbidity in patients admitted to the surgical intensive care unit (ICU) who were randomly assigned to intensive insulin therapy $(n=765)$. This was initiated when blood glucose was $>6.1 \mathrm{mmol} / 1(110 \mathrm{mg} / \mathrm{dl})$, with a goal glucose level of 4.4-6.1 mmol/1 $(80-110 \mathrm{mg} / \mathrm{dl})$. The study group was compared with patients randomised to conventional insulin therapy $(n=783)$, which was initiated when blood glucose was $>11.9 \mathrm{mmol} / \mathrm{l}(215 \mathrm{mg} / \mathrm{dl})$, with a goal glucose level of $10.0-11.1 \mathrm{mmol} / \mathrm{l}(180-200 \mathrm{mg} / \mathrm{dl})$. The study showed that ICU mortality decreased from 8.0 to $4.6 \%$, attributable to an effect among patients who remained in the ICU for more than 5 days, in the patients who received intensive insulin therapy. Hospital mortality was decreased from 10.9 to $7.2 \%$. Several morbidity endpoints were also decreased in the intensive insulin therapy patients (Table 1), but hypoglycaemia (blood glucose $<2.2 \mathrm{mmol} / 1[40 \mathrm{mg} / \mathrm{dl}]$ ) was increased six-fold.

Multivariate logistic regression analysis indicated that lower blood glucose concentrations, rather than higher insulin doses, were related to reduced mortality, critical illness polyneuropathy, bacteraemia, inflammation and anaemia (but not acute renal failure) [2]. Potential mechanisms of the beneficial effects of intensive insulin therapy, which have been reviewed [3], are those possibly related to lower glucose or to higher insulin levels. The former include improved macrophage/neutrophil function [3],

P. E. Cryer $(\bowtie)$

Division of Endocrinology, Metabolism and Lipid Research (Campus Box 8127), Washington University School of Medicine, 660 South Euclid Avenue,

St Louis, MO 63110, USA

e-mail: pcryer@wustl.edu improved coagulation and fibrinolysis [2], and reduced superoxide production (which might relate to improved hepatocyte mitochondrial function [3, 4]); if extended to neurons, the latter might explain prevention of critical illness polyneuropathy $[3,5]$. In addition to anabolic and anti-inflammatory actions [3], other beneficial effects of insulin may have been operative [3]. In a subset of patients requiring intensive care for more than 7 days, lipid, rather than glucose, control was associated with beneficial effects of intensive insulin therapy on morbidity and mortality [6]. Finally, the findings of reduced levels of circulating adhesion molecules, reduced inducible nitric oxide synthase gene expression in post-mortem liver and skeletal muscle, and lowered circulating nitric oxide levels associated with intensive insulin therapy suggest protection of endothelial function [7].

Among other issues [8], limitations of the surgical ICU study included concerns that it was not strictly blinded and that cardiac surgery patients were over-represented [1]; the latter issue has since been addressed in a study on intensive insulin therapy in medical ICU patients [9]. The experimental design was similar to that of the surgical ICU study. Patients were again randomly assigned to intensive insulin therapy ( $n=595 ; 98 \%$ treated with a median insulin dose of $59 \mathrm{U}$ per ICU day) or to conventional insulin therapy $(n=605 ; 70 \%$ treated with a median insulin dose of $10 \mathrm{U}$ per ICU day).

Compared with conventional insulin therapy, intensive therapy reduced some of the morbidity endpoints, including acquired kidney injury, time to weaning from mechanical ventilation, and time to discharge from the ICU and from the hospital (Table 1). These were again attributable to an effect among patients who remained in the ICU for more than 5 days. However, in contrast to the surgical ICU findings, intensive insulin therapy did not decrease bacter- 
Table 1 Effect of intensive insulin therapy in two ICU studies

\begin{tabular}{|c|c|c|}
\hline Endpoint & $\begin{array}{l}\text { Surgical ICU } \\
{[1]}\end{array}$ & $\begin{array}{l}\text { Medical ICU } \\
{[9]}\end{array}$ \\
\hline Mortality & Decreased & Not decreased \\
\hline \multicolumn{3}{|l|}{ Morbidity } \\
\hline Acute kidney injury & Decreased & Decreased \\
\hline $\begin{array}{l}\text { Critical illness } \\
\text { polyneuropathy }\end{array}$ & Decreased & (Not reported) \\
\hline Prolonged ventilatory support & Decreased & Decreased \\
\hline ICU stay & Decreased & Decreased \\
\hline Hospital stay & Not decreased & Decreased \\
\hline Bacteraemia & Decreased & Not decreased \\
\hline Prolonged antibiotic therapy & Decreased & Not decreased \\
\hline Need for dialysis & Decreased & Not decreased \\
\hline Hyperbilirubinaemia & Decreased & Not decreased \\
\hline Red blood cell transfusions & Decreased & (Not reported) \\
\hline Use of ICU resources & Decreased & Not decreased \\
\hline Hypoglycaemia & Increased & Increased \\
\hline
\end{tabular}

aemia or the need for prolonged antibiotic therapy. It did not reduce hyperbilirubinaemia, or the need for dialysis or use of ICU resources (Table 1). Nor did it decrease hyperinflammation, although this, as well as hyperbilirubinaemia and use of ICU resources, was decreased in those patients who remained in the ICU for more than 3 days.

In contrast to the findings in surgical ICU patients, intensive insulin therapy did not reduce mortality in the medical ICU patients. In the intensive insulin therapy group, $24.2 \%$ of the patients died in the ICU and $37.3 \%$ died in the hospital. In the conventional insulin therapy group, $26.8 \%$ of the patients died in the ICU and $40.0 \%$ died in the hospital. Among the 433 patients who stayed in the ICU for less than 3 days there were more deaths during intensive insulin therapy $(n=56,12.9 \%)$ than during conventional insulin therapy $(n=42,9.7 \%)$. Among the 767 patients who stayed in the ICU for more than 3 days there were fewer deaths during intensive insulin therapy than during conventional therapy in the ICU (31.3 vs $38.1 \%)$ and in the hospital (43.0 vs $52.5 \%$ ). The latter was least apparent in the patients in the highest Acute Physiology and Chronic Health Evaluation (APACHE) II quartile.

Intensive insulin therapy increased the incidence of hypoglycaemia (a blood glucose concentration $<2.2 \mathrm{mmol} / 1[40 \mathrm{mg} / \mathrm{dl}]$ ) by six-fold in both studies $[1,9]$. Among the medical ICU patients, $18.7 \%$ of those in the intensive insulin therapy group and $3.1 \%$ of those in the conventional insulin therapy group had such glucose levels detected, and the incidence of two or more such episodes was increased nearly five-fold in the intensive insulin therapy group [9]. The incidence of less marked hypoglycaemia was not reported. Haemodynamic deterioration, convulsions or other events were not noted during hypoglycaemic episodes. Nonetheless, objective hypoglycaemic morbidity, with a mean blood glucose concentration of $1.8 \mathrm{mmol} / \mathrm{l} \quad(32 \mathrm{mg} / \mathrm{dl})$, was demonstrably increased during intensive insulin therapy. Furthermore, logistic regression analysis identified hypoglycaemia as an independent risk factor for death.

Absolute or relative insulin excess, with inadequate or interrupted provision of exogenous carbohydrate, together with features of critical illness that limit endogenous glucose production and accelerate glucose utilisation [10], was undoubtedly the fundamental cause of hypoglycaemia in the ICU. In patients on intensive insulin therapy, insulin was infused intravenously in doses, based on blood glucose measurements at intervals of $1-4 \mathrm{~h}$, and intended to achieve and maintain normal blood glucose concentrations. Thus, in contrast to normal minute-to-minute glucose-regulated endogenous insulin secretion, exogenous insulin administration was necessarily imperfect and circulating insulin levels were largely unregulated by ambient glucose levels. In addition, it is conceivable that physiological defences against hypoglycaemia - decrements in insulin, and increments in glucagon and epinephrine [11] - were compromised in the critically ill patients. Although endogenous insulin secretion probably decreased as blood glucose levels declined within the physiological postabsorptive range in some of the patients, this would not occur in patients with an endogenous insulin deficiency ( $17 \%$ of the medical ICU patients had known diabetes mellitus) or, perhaps, in those with stress-induced suppression of endogenous insulin secretion. Glucagon and epinephrine responses to falling glucose levels might have been reduced by prior hypoglycaemic episodes [12]—including subphysiological glucose levels considerably higher than the value of $2.2 \mathrm{mmol} / 1(40 \mathrm{mg} / \mathrm{dl})$ used by the authors to define hypoglycaemia — or, to the extent they mimic sleep [13], by sedation or medical causes of reduced consciousness. The latter, of course, would preclude the normal behavioural defence: ingestion of food based on the perception of symptoms of hypoglycaemia. There are also many other causes of hypoglycaemia [10] that might have been operative: drugs other than insulin (e.g. quinolone antibiotics), sepsis, hepatic, renal or cardiac failure, and other hormone (e.g. glucocorticoid) deficiencies. Finally, in a process performed repeatedly $24 \mathrm{~h}$ per day, day after dayblood glucose measurement, determination of the insulin dose, infusion of insulin, and provision of parenteral or enteral nutrition - there is always the possibility of the occasional human error.

It is not entirely clear why intensive insulin therapy was less beneficial in the medical ICU [9] than in the surgical ICU [1]. Based on the mortality rates, it seems clear that the medical ICU patients were more seriously ill. Since both 
studies indicate that the benefits of intensive insulin therapy accrue over time, higher early mortality would be expected to dilute any mortality benefit and perhaps several morbidity benefits. Other differences in the patient populations are probably relevant. For example, the fact that sepsis is more likely to prompt admission to a medical ICU might explain the failure of intensive insulin therapy to decrease bacteraemia. The only adverse effect of intensive insulin therapy identified was hypoglycaemia. Although this was not observed to cause any deaths, hypoglycaemia can be fatal, and was identified statistically as an independent risk factor for death in the medical ICU [9]. Thus, as the authors acknowledge, it is conceivable that the beneficial effects of intensive insulin therapy were offset by the detrimental effects of hypoglycaemia, which could include adverse effects on the brain or of the triggering of a cardiac event that was not recognised. This possibility raises a critical question: is iatrogenic hypoglycaemia the limiting factor in the glycaemic management of the critically ill, just as it is in the short- and long-term glycaemic management of diabetes [12]?

Reproducibly reduced mortality is compelling evidence of benefit from a given therapeutic intervention. Reproducibly reduced morbidity is evidence of benefit, provided that it is not offset by an increase in other morbidity. The mortality benefit of intensive insulin therapy with a goal of euglycaemia, reported in a randomised study in a surgical ICU [1] and in a non-randomised study in a medicalsurgical ICU [14], has not been reproduced in a randomised study in a medical ICU [9]. Some of the reported morbidity benefits of intensive insulin therapy [1] have been reproduced [9] (Table 1), but the possible adverse effect of hypoglycaemia has been acknowledged. Until a favourable benefit-risk relationship is established in rigorous clinical trials, it would appear that euglycaemia is not an appropriate goal during critical illness in the routine clinical setting with current treatment methods. (That goal will be more safely achieved when reliable and accurate glucose sensors that make glucose-regulated insulin replacement feasible become available [15]). Nonetheless, some degree of glycaemic control during critical illness is justifiable on the basis of theory and the available evidence from two randomised clinical trials (1-9). Based on their statistical analysis of the relationships between ICU mortality and glycaemia, Finney and colleagues [16] suggested a mortality benefit for an upper blood glucose limit of $8.0 \mathrm{mmol} / \mathrm{l}(144 \mathrm{mg} / \mathrm{dl})$. However, a post hoc analysis of the data from patients staying in the surgical ICU for longer than 5 days [1] suggested a gradual decrease in the risk of ICU and hospital mortality with decreasing blood glucose levels without an identifiable threshold, and that for the occurrence of several morbidities - critical illness polyneuropathy, bacteraemia, acute renal failure and red blood cell transfusion - the risk was lower among patients with euglycaemia than those with blood glucose levels that were in the $6.1-8.3 \mathrm{mmol} / 1(110-150 \mathrm{mg} / \mathrm{dl})$ range [2]. Clearly, the optimal glycaemic goal in the critically ill remains to be determined $[16,17]$.

Acknowledgements The author's work cited was supported, in part, by US Public Health Service/National Institutes of Health grants R37 DK27085, M01 RR00036, P60 DK20579 and T32 DK07120, and a postdoctoral fellowship award from the American Diabetic Association.

Duality of interest statement The author has served as a member of Advisory Boards of Novo Nordisk Pharmaceuticals, Takeda Pharmaceuticals and MannKind Pharmaceuticals in recent years, and of other pharmaceutical firms in earlier years.

\section{References}

1. Van den Berghe G, Wouters P, Weekers F et al (2001) Intensive insulin therapy in critically ill patients. $N$ Engl $\mathrm{J}$ Med 345:1359-1367

2. Van den Berghe G, Wouters PJ, Bouillon R et al (2003) Outcome benefit of intensive insulin therapy in the critically ill: insulin doses versus glycemic control. Crit Care Med 31: 359-366

3. Van den Berghe G (2004) How does blood glucose control with insulin save lives in intensive care? J Clin Invest 114: $1187-1195$

4. Vanhorebeek I, De Vos R, Mesotten D, Wouters PJ, De WolfPeeters C, Van den Berghe G (2005) Protection of hepatocyte mitochondrial ultrastructure and function by strict blood glucose control with insulin in critically ill patients. Lancet 365:53-59

5. Van den Berghe G, Schoonheydt K, Becx P, Bruyninckx F, Wouters PJ (2005) Insulin therapy protects the central and peripheral nervous system of intensive care patients. Neurology 64:1348-1353

6. Mesotten D, Swinnen JV, Vanderhoydonc F, Wouters PJ, Van den Berghe G (2004) Contribution of circulating lipids to the improved outcome of critical illness by glycemic control with intensive insulin therapy. J Clin Endocrinol Metab 89:219-226

7. Langouche L, Vanhorebeek I, Vlasselaers D et al (2005) Intensive insulin therapy protects the endothelium of critically ill patients. $\mathrm{J}$ Clin Invest 115:2277-2286

8. Bellomo R, Egi M (2005) Glycemic control in the intensive care unit: why we should wait for NICE-SUGAR. Mayo Clin Proc 80:1546-1548

9. Van den Berghe G, Wilmer A, Hermans G et al (2006) Intensive insulin therapy in the medical ICU. N Engl J Med 354:449-461

10. Cryer PE (2003) Glucose homeostasis and hypoglycemia. In: Larsen PR, Kronenberg H, Melmed S, Polonsky K (eds) Williams textbook of endocrinology, 10th edn. Saunders, Philadelphia, pp $1585-1618$

11. Cryer PE (2001) The prevention and correction of hypoglycemia. In: Jefferson LS, Cherrington AD (eds) Handbook of physiology. Section 7, the endocrine system. Volume II, The endocrine pancreas and regulation of metabolism. Oxford University Press, New York, pp 1057-1092 
12. Cryer PE (2004) Diverse causes of hypoglycemia-associated autonomic failure in diabetes. N Engl J Med 350:2272-2279

13. Banarer S, Cryer PE (2003) Sleep-related hypoglycemia-associated autonomic failure in type 1 diabetes: reduced awakening from sleep during hypoglycemia. Diabetes 52:1195-1203

14. Krinsley JS (2004) Effect of intensive glucose management protocol on the mortality of critically ill adult patients. Mayo Clin Proc 79:992-1000
15. Hovorka R (2005) Continuous glucose monitoring and closedloop systems. Diabet Med 23:1-12

16. Finney SJ, Zekveld C, Elia A, Evans TW (2003) Glucose control and mortality in critically ill patients. JAMA 290:20412047

17. Van den Berghe G (2004) Tight blood glucose control with insulin in 'real-life' intensive care. Mayo Clin Proc 79:977-978 